\title{
Comparison of systems combining auxins with thidiazuron or kinetin supplemented with polyvinylpirrolidone during embryogenic callus induction in three Theobroma cacao L. genotypes
}

\author{
Modeste Kan KOUASSI ${ }^{1 *}$, Edmond Kouablan KOFFI ${ }^{2}$, Oumar SILUE ${ }^{1,2}$, \\ Mathias Gnion TAHI $^{3}$, Mah TOURE ${ }^{2}$ and Eugène Pacôme Kouakou KONAN ${ }^{4}$ \\ ${ }^{1}$ Laboratoire de Physiologie Végétale, UFR Biosciences, Université Félix Houphouët-Boigny, \\ 22 P 582 Abidjan 22, Côte d'Ivoire. \\ ${ }^{2}$ Laboratoire Central de Biotechnologies (LCB), Centre National de Recherche Agronomique (CNRA), KM \\ 17 Route de Dabou, 01 BP 1740 Abidjan 01, Côte d'Ivoire. \\ ${ }^{3}$ Programme Cacao, Centre National de Recherche Agronomique (CNRA), Station de Recherche de Divo, \\ BP 808 Divo, Côte d'Ivoire. \\ ${ }^{4}$ Programme Palmier à Huile, Centre National de Recherche Agronomique (CNRA), Station de Recherche \\ de La Mé, 13 BP 989 Abidjan 13, Côte d'Ivoire. \\ "Corresponding author; E-mail: kanmodestekouassi@gmail.com
}

\section{ACKNOWLEDGEMENTS}

The funds for this study were graciously donated by Mars Incorporated and the National Centre of Agronomic Research (CNRA, in French) of Côte d'Ivoire.

\begin{abstract}
For two decades, the combination 2,4-dichlorophenoxyacetic acid (2,4-D)/thidiazuron (TDZ) has been the most used to induce somatic embryogenesis in cocoa. The aim of this study was to compare the effect of combination systems, auxin/TDZ and auxin/kinetin (Kin) systems, as well as the addition of polyvinylpirrolidone (PVP) to these combinations on the induction of embryogenic calli in cocoa (Theobroma cacao L.). To this end, eight induction media combining auxin 2,4-dichlorophenoxyacetic acid (2,4-D) or 2,4,5-trichlorophenoxyacetic acid (2,4,5-T) at 4,5 mM with cytokinin thidiazuron (TDZ) $(22.8 \mathrm{nM})$ or kinetin (Kin) $(1.125 \mathrm{mM})$ supplemented or not with PVP $(300 \mathrm{mg} / \mathrm{L})$ were evaluated on induction of embryogenic callus with petals or staminodes in three genotypes of cocoa. The basal salts medium was DKW (Driver and Kuniyuki Walnut medium). This study showed that the effect of 2,4-D combinations with Kinetin or TDZ was statistically identical on the induction of embryogenic callus. On the other hand, with 2,4,5-T, the association with Kin was more embryogenic than with TDZ. Furthermore, addition of PVP improved the induction of embryogenic callus in both combination systems. In the presence of PVP, media containing 2,4,5-T exhibited higher levels of embryogenic callus induction than their counterparts containing 2,4-D. This study allows the expansion of the possibilities of induction of embryogenic callus in cocoa.
\end{abstract}

(ㅇ) 2018 International Formulae Group. All rights reserved.

Keywords: somatic embryogenesis, cocoa, petal, growth regulator, staminode, antioxidant.

\section{INTRODUCTION}

Cocoa (Theobroma cacao L.) is a small neotropical tree, evergreen, native of the undergrowth of the Amazon Rainforest (South America), and belongs to the Malvaceae family. It is grown mainly for its beans used 
as raw material in the manufacture of food, pharmaceutical and cosmetic products (Dillinger et al., 2000). Cocoa contains phenols, flavonoids and its antioxidant properties are higher than black tea, green tea or red wine (Subhashini et al., 2010; Yapo et al., 2013). Over the past decade, its consumption has increased due to the functional properties conferred by these antioxidant polyphenols. The beneficial effects of cocoa on cancer, diabetes control, cardiovascular disease and hepatitis prevention have been reported by several authors (Rusconi and Conti 2010, Sarmadi et al., 2011, 2012). Cocoa plays an important economic role as a source of foreign exchange in many tropical countries, including Côte d'Ivoire. Therefore, its culture provides substantial income to smallholders in the tropics (Alemanno et al., 2003).

Theobroma cocoa is usually a heterozygous plant with a high variability for agronomic and quality traits. Seed propagation, although effective, is problematic because many trees are unproductive. The number of planting materials produced by rooted cuttings and grafting is unbalanced and insufficient to meet the demand of farmers. Therefore, it is necessary to accelerate the production of elite cocoa planting materials using alternative methods such as somatic embryogenesis. Somatic embryo production and seedling regeneration have been performed in a large number of genotypes ( $\mathrm{Li}$ et al., 1998, Maximova et al., 2002).

Despite the current progress in this area (Traore et al., 2003 ; Minyaka et al., 2010; Florez et al., 2015) the reported efficiencies of somatic embryogenesis and plant regeneration obtained remain low. Furthermore, the practical utilization of this technology for clonal propagation remains hindered by the inability to induce somatic embryogenesis from a majority of elite cocoa genotypes (Da Silva et al., 2008). For these applications to be technically and economically feasible, it is essential to optimize the system variables to obtain high multiplication rates of quality somatic embryos (Traore and Guiltinan, 2006).
Over the past two decades, the majority of studies on somatic embryogenesis of cocoa based on $\mathrm{Li}$ et al. (1998) protocol used 2,4-D and thidiazuron (TDZ) as growth regulators during the induction phase of somatic embryogenesis. The use of 2,4-D and TDZ during the induction phase of somatic embryogenesis is referred to as the "2,4-D / TDZ system" in this paper. Our recent studies have shown the positive influence of the system "auxin/Kin" on induction of embryogenic calli that used combinations of 2,4-D/Kin and 2,4,5-T/Kin (Kouassi et al., 2017a). In addition, PVP tested in the 2,4D/TDZ system improved the induction of embryogenic calli (Kouassi et al., 2017b). As a reminder, these two systems used DKW medium as a basal mineral solution. However, the 2,4-D/TDZ system uses 2,4-D and thidiazuron (TDZ) as growth regulators for the first fourteen days of the callus induction phase, also known as Primary Callus Growth (PCG). ). This first phase is followed by a second fourteen days phase in which 2,4-D and 6-benzylaminopurine (BAP) are used. After this second phase, cultures are transferred to an embryo development (ED) medium ( $\mathrm{Li}$ et al., 1998). In the auxin/kin system, 2,4,5-T or 2,4-D are separately combined with kinetin during the 28 days of the induction phase. Cultures are then directly transferred onto an embryo development medium.

From what we know, there is no work on somatic embryogenesis of cocoa that had first (1) evaluated the effect of adding PVP to an auxin/kin system, secondly (2) the effect of the combination 2,4,5-T/TDZ and thirdly (3) compared the 2,4-D/TDZ and auxin/Kin systems on the induction of embryogenic callus. This study aimed at comparing these two combination systems and the effect of PVP addition in each of these systems. The comparison criterion was the rate of induction of embryogenic callus.

\section{MATERIALS AND METHODS Plant material}

About 4 to $5 \mathrm{~mm}$ long flower buds were collected (early in the morning before 9:00 am) during rainy season in June 2016, 
from trees of three elite genotypes coded $\mathrm{C} 1$, $\mathrm{C} 8$ and $\mathrm{C} 14$ from the National Centre for Agronomic Research experimental farm in Divo (Côte d'Ivoire). Genotypes C1 and C14 are originated from Côte d'Ivoire whereas $\mathrm{C} 8$ is from Trinidad.

\section{Preparation of explants}

The flower buds were surfacesterilized using $1 \% \quad(\mathrm{w} / \mathrm{v})$ calcium hypochlorite for $20 \mathrm{~min}$. Then they were rinsed four times in sterile distilled water and afterwards sliced perpendicularly to their longitudinal axis with a sterile scalpel blade. Petals and staminodes were extracted with a sharp sterile forceps and were used as explants.

\section{Media}

All media were defined using DKW (Driver and Kuniyuki Walnut medium, 1984) basal salts. Two induction media groups were prepared with this basal medium. In the first group of four induction media, auxin 2,4-D or 2,4,5-T at $4.5 \mu \mathrm{M}$ was combined with cytokinin TDZ $(22.8 \mathrm{nM})$ or Kin $(1.125 \mu \mathrm{M})$. In the second group also comprising four induction media, PVP $(300 \mathrm{mg} / \mathrm{L})$ was added to each of the combinations (auxin/cytokinin) of the first group. After fourteen days, cultures on induction media containing TDZ were first transferred for fourteen other days to secondary calli growth (SCG) medium and finally transferred to an embryo development (ED) medium. As for cultures carried out on induction medium containing kinetin, after twenty-eight days, they were directly transferred to the embryo development medium (Kouassi et al., 2017b). The SCG, ED media and additional substances in induction media such as vitamins and carbon source were prepared according to the protocol of $\mathrm{Li}$ et al. (1998). The eight induction media enabled the evaluation of the effect on the induction of embryogenic calli of the system using TDZ or Kinetin as well as the addition of PVP to these two systems.

\section{Culture conditions}

The $\mathrm{pH}$ was adjusted to 5.8 into induction media or to 5.7 into SCG and ED media using solutions of $0.1 \mathrm{~N} \mathrm{NaOH}$ or $\mathrm{HCl}$. Culture media were solidified with Phytagel $(2 \mathrm{~g} / \mathrm{L})$ and then autoclaved for $20 \mathrm{~min}$ at 121 ${ }^{\circ} \mathrm{C}$ under $100 \mathrm{KPa}$ pressure. After sterilization, the culture media were poured in sterile Petri dishes under a laminar flow hood. Incubations were carried out in a culture room in continuous darkness with a temperature of $24 \pm 1{ }^{\circ} \mathrm{C}$ and a relative humidity of $70 \%$. The Petri dishes were arranged on racks according to a completely randomized design.

\section{Evaluation of embryogenic callus induction}

After twelve weeks of culture, embryogenic callus was evaluated on ED medium. The rate of embryogenic calli (REC) was calculated as follows:

REC $=($ Number of callogenic explants that formed somatic embryos / Total number of callogenic explants) x 100

\section{Statistical analysis}

Collected data were submitted to analysis of variance (ANOVA) with the Xlstat 2014 software. For unequal numbers, analysis of variance using generalized linear model (GLM) was adopted. When a significant difference was observed between treatments, the Newman-Keuls multi-range test at a threshold of $5 \%$ was used to separate the means.

\section{RESULTS}

\section{Ability of tested clones and explants to} induce somatic embryos

With respectively 22.11 and 14.32 of mean percentage of embryogenic calli, the clones $\mathrm{C} 1$ and $\mathrm{C} 14$ were the most embryogenic. Only $0.03 \%$ of petals responded to somatic embryogenesis in clone C8. This clone showed partial recalcitrance to somatic embryogenesis. As for explants, the petals were the most embryogenic. Embryogenic events were almost non-existent (0.14 mean percentage of embryogenic calli in both $\mathrm{C} 1$ and $\mathrm{C} 14$ ) with staminodes (Table 1 , Figure 1). 


\section{Comparison of Auxin/Kinetin and Auxin/TDZ systems}

The effect of 2,4-D combinations with Kin or TDZ was statistically similar. In contrast, with 2,4,5-T, the embryogenic response was different depending on the type of cytokinin. Indeed, the combination with Kin was more embryogenic $(24.78 \%)$ than with TDZ (17.01\%). The percentages of embryogenic callus were at least two times higher with 2,4,5-T than with 2,4-D (Table 2).

\section{Effect of PVP addition on Auxin/Cytokinin combinations}

The addition of PVP in media with combination 2,4-D / Kin or 2,4,5-T / TDZ increased the mean percentage of embryogenic calli. Overall, the addition of PVP improved or at least maintained the embryogenic callus rate. In the presence of PVP, media containing 2,4,5-T exhibited higher levels of embryogenic callus induction than their counterparts with 2,4-D (Table 3).

Table 1: Effects of genotype and explant on embryogenic calli induction in cocoa (Theobroma cacao L.).

\begin{tabular}{lcc}
\hline Genotypes & Explants & Mean percentage of embryogenic calli \\
\hline C1 & staminodes & $0.14 \pm 0.01 \mathbf{c}$ \\
& Petals & $22.11 \pm 2.49 \mathbf{~ a}$ \\
\hline C8 & staminodes & $0.00 \mathbf{c}$ \\
& Petals & $0.03 \pm 0.00 \mathbf{c}$ \\
\hline C14 & staminodes & $0.14 \pm 0.01 \mathbf{c}$ \\
& Petals & $14.32 \pm 1.65 \mathbf{~ b}$
\end{tabular}

Data are presented as mean percentage \pm standard error (SE). Values in each column of explant followed by the same letters (superscript) do not differ statistically at $\mathrm{p}<0.05$ according to Newman-Keuls' test.

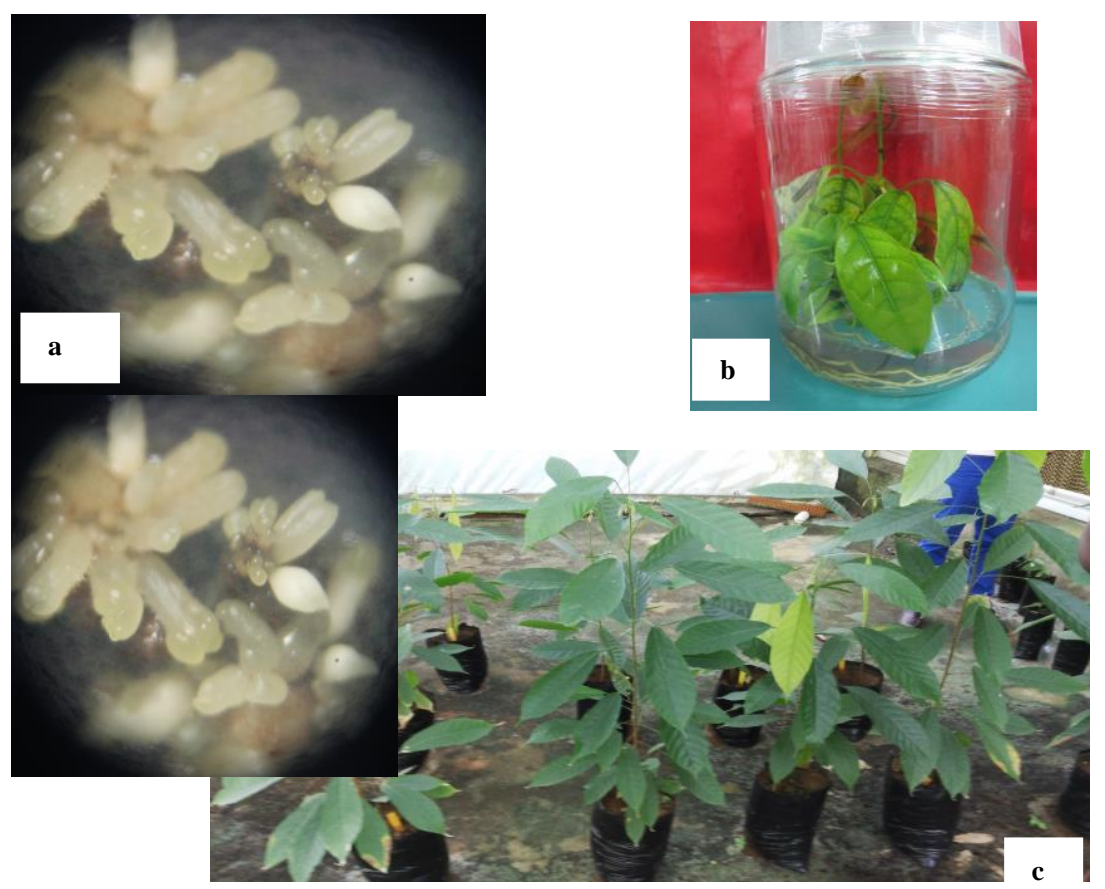

Figure 1: Somatic embryogenesis in cocoa (Theobroma cacao L.). (a) Somatic embryos; (b) regenerated plantlets from somatic embryos and (c) cocoa plants from somatic embryogenesis in greenhouse. 
Table 2: Effect of auxin/cytokinin combinations on embryogenic calli induction from petals in three cocoa (Theobroma cacao L.) genotypes.

\begin{tabular}{lcc}
\hline Auxin & Cytokinin & Mean percentage of embryogenic calli \\
\hline $2,4-\mathrm{D}$ & Kin $(1.125 \mu \mathrm{M})$ & $7.63 \pm 0.51 \mathbf{c}$ \\
$(4.5 \mu \mathrm{M})$ & $\mathrm{TDZ}(22.8 \mathrm{nM})$ & $6.96 \pm 0.47 \mathbf{c}$ \\
& Kin $(1.125 \mu \mathrm{M})$ & $24.78 \pm 2.19 \mathbf{a}$ \\
$(4.5 \mu \mathrm{M})$ & $\mathrm{TDZ}(22.8 \mathrm{nM})$ & $17.01 \pm 0.99 \mathbf{b}$ \\
\end{tabular}

Data are presented as mean percentage \pm standard error (SE). Values in each column of explant followed by the same letters (superscript) do not differ statistically at $\mathrm{p}<0.05$ according to Newman-Keuls' test.

Table 3: Effect of polyvinylpirrolidone addition on embryogenic calli induction from petals in three cocoa (Theobroma cacao L.) genotypes.

\begin{tabular}{lcc}
\hline Combination Auxin / Cytokinin & PVP & Average rate of embryogenic calli \\
\hline $2,4-\mathrm{D} / \mathrm{Kin}(4.5 \mu \mathrm{M} / 1.125 \mu \mathrm{M})$ & 0 & $6.96 \pm 0.46 \mathbf{c}$ \\
& $300 \mathrm{mg} / \mathrm{L}$ & $14.03 \pm 1.54 \mathbf{~ b}$ \\
\hline $2,4-\mathrm{D} / \mathrm{TDZ}(4.5 \mu \mathrm{M} / 22.8 \mathrm{nM})$ & 0 & $6.02 \pm 0.37 \mathbf{~ c}$ \\
& $300 \mathrm{mg} / \mathrm{L}$ & $7.63 \pm 0.56 \mathbf{c}$ \\
\hline $2,4,5-\mathrm{T} / \mathrm{Kin}(4.5 \mu \mathrm{M} / 1.125 \mu \mathrm{M})$ & 0 & $25.43 \pm 2.21 \mathbf{a}$ \\
& $300 \mathrm{mg} / \mathrm{L}$ & $29.18 \pm 3.01 \mathbf{a}$ \\
\hline $2,4,5-\mathrm{T} / \mathrm{TDZ}(4.5 \mu \mathrm{M} / 22.8 \mathrm{nM})$ & 0 & $15.37 \pm 1.82 \mathbf{~ b}$ \\
& $300 \mathrm{mg} / \mathrm{L}$ & $24.14 \pm 2.17 \mathbf{~ a}$
\end{tabular}

Data are presented as mean percentage \pm standard error (SE). Values in each column of explant followed by the same letters (superscript) do not differ statistically at $\mathrm{p}<0.05$ according to Newman-Keuls' test.

\section{DISCUSSION}

Previous studies as well as this one reported that petals were more embryogenic than staminodes. This is consistent with the C1 genotype (Kouassi et al., 2017a). The best response observed in the petals indicates that both auxins/cytokinins systems, namely auxin/Kin and auxin/TDZ, did not induce embryogenesis differently. Indeed, both combinations have favored embryogenesis from the petals. These results are in agreement with those of Kouassi et al. (2017a) who used the auxin/Kin system and Issali et al. (2008) who used the auxin/TDZ system. However, other authors (Li et al., 1998; Tan and Furtek, 2003) obtained a better embryogenic response with staminodes using auxin/TDZ system. Based on conclusions from studies carried out by these authors, it seems more likely - under current experimental conditions - that explants embryogenic response is much more genotype dependent than medium dependent. However, further modifications of medium culture could influence embryogenic response favorably either to staminode or petal poles. For example, in wheat (Triticum aestivum L.), a mature embryo, an immature embryo, an endosperm-supported mature embryo and an apical shoot meristem were cultured on four callus induction media. The results showed that the in vitro culture response of explants taken from the same plant varied from one another and was influenced by the genotype and composition of the media (Mahmood and Razzaq, 2017).

In general, the system auxin/Kin had average levels of embryogenic callus equal or superior to those of auxin/TDZ system. Early 
studies using TDZ (phenylurea cytokinin) during somatic embryogenesis in cocoa have led to an embryogenic response in a large number of genotypes, contrary to the usual responses obtained with cytokinins of adenine, Kin, BAP and zeatin types ( $\mathrm{Li}$ et al., 1998). The current study confirmed our previous work (Kouassi et al., 2017a) which showed that a good embryogenic response is obtained with adenine-type cytokinins, in particular with Kin. But it also shows that in particular conditions, Kin could improve the induction of embryogenic callus compared with TDZ. These conditions could be, on the one hand, the mineral solution, and on the other hand, the genotype. Indeed, the first tests with Kin (Lopez-Baez et al., 2000) used the mineral elements of Murashige and Skoog (1962) whereas the test involving the TDZ used only the mineral elements of DKW (Li et al., 1998). Therefore, there were no tests comparing the two types of cytokinins on the same mineral solution. This did not enable the comparison of the adenine and phenylureatype cytokinins on the same basis and beyond the auxin/Kin and auxin/TDZ combinations systems. So there could be a bias. Indeed, the DKW mineral solution itself is a cocktail favoring somatic embryogenesis induction. This solution, which was developed for in vitro propagation of some woody perennial species, provided a higher concentration of calcium, sulfur, and magnesium than MS medium. These elements are essential for cell differentiation and somatic embryogenesis (Pedroso et al., 1996). The importance of the contribution of elements such as sulfur to the induction of somatic embryogenesis in cocoa has been demonstrated (Minyaka et al., 2010). This study, which improves the basis of comparison using the same mineral solution for both systems of combination, brings us closer to the right conclusion. The second factor to consider is the genotype. Indeed, this study was based only on three genotypes. The previous was on five genotypes (Kouassi et al., 2017). Thus, observations made on a relatively small number of genotypes could not be extrapolated to all cocoa genotypes. Therefore, other genotypes may be more reactive with the combination system auxin/TDZ compared with combinations auxin/Kin.

Our previous studies dealing with PVP addition to the 2,4-D/TDZ combination indicated an optimization of the rate of embryogenic calli (Kouassi et al., 2017b). It was also noted that PVP is compatible with both auxin/Kin and auxin/TDZ systems for optimizing the rate of embryogenic callus. The use of the antioxidant PVP would avoid the accumulation of toxic phenolic compounds for the induction of somatic embryos. The positive effect of PVP on somatic embryogenesis was already observed in other plants. With the bitter melon (Momordica charantia L.), MS medium with full concentration containing $50 \mathrm{mg} / \mathrm{L}$ PVP was effective in achieving a high frequency induction, maturation and somatic embryo development (Thiruvengadam et al., 2006). In Podophyllum hexandrum Royle, medium with $3 \mathrm{~g} / \mathrm{L}$ PVP produces a maximum number of somatic embryos (Rajesh et al., 2014).

\section{Conclusion}

To our knowledge, this study made it possible for the first time to evaluate the effect of PVP in a protocol for cocoa somatic embryos induction based on two auxins, 2,4-D and 2,4- 5-T combined separately with kinetin. It also evaluated the effect of 2,4,5T/TDZ combination. Finally, it enables the comparison of embryogenic callus induction protocols using either TDZ or Kin. It was also shown that on DKW medium, 2,4-D/Kin and 2,4-D/TDZ systems give comparable results. On the other hand, with the 2,4,5-T, the rate of embryogenic calli was higher with Kin than with TDZ. Therefore, the combination 2,4,5T/Kin could be widely exploited to induce embryos. In addition, it has been confirmed that supplementing PVP improves the somatic embryos formation. This study allowed expanding the possibilities of induction of embryogenic callus in cocoa.

\section{COMPETING INTERESTS}

The authors declare that there are no competing interests. 


\section{AUTHORS' CONTRIBUTIONS}

MKK contributed in the conception of the protocol, laboratory activities, data analysis and manuscript writing. MT and OS contributed in laboratory activities and data collection. EKK, MGT and EPKK contributed in reading and correcting the manuscript for the final version before submission. All the authors participated in the review of the manuscript.

\section{ACKNOWLEDGEMENTS}

Thanks very much to Mr BAZIE Jules and Ms N'Diaye Adja for their contribution to the improvement of this manuscript language level.

\section{REFERENCES}

Alemanno L, Ramos T, Gargadenec A, Andary C, Ferriere N. 2003. Localization and identification of phenolic compounds in Theobroma cacao L. somatic embryogenesis. An Bot., 92(4): 613-623. http://dx.doi:10.1093/aob/mcg177

Da Silva TER, Gidade LC, Alvin FC, de Mattos-Cascardo C, Costa MGC. 2008. Somatic embryogenesis and plant regeneration in elite clones of Theobroma cacao L. Pesq. agropec. bras. Brasília, 43(10): 1433-1436. http://dx.doi.org/10.1590/S0100204X2008001000024

Dillinger TL, Barriga P, Escárcega S, Jimenez M, Lowe DS, Grivetti LE. 2000. Food of the Gods: Cure for humanity? A cultural history of the medicinal and ritual use of chocolate. J Nutr., 130(8): 2057-2072. http://jn.nutrition.org/content/130/8/2057 S.long\#abstract-1

Driver JA, Kuniyuki AH. 1984. In vitro propagation of paradox walnut root stock. Hortsci., 19: 507-509. http://citeseerx.ist.psu.edu/viewdoc/dow nload?doi=10.1.1.920.6727\&rep=rep1\&t ype $=$ pdf

Florez SL, Erwin RL, Maximova SN, Guiltinan MJ, Curtis WR. 2015. Enhanced somatic embryogenesis in Theobroma cacao using the homologous
BABY BOOM transcription factor. $B M C$ Plant Biol., 121. https://doi.org/10.1186/s12870-015$\underline{0479-4}$

Issali AE, Traoré A, Koffi KE, Ngoran JAK, Sangaré A. 2008a. Characterization of callogenic and embryogenic abilities of some genotypes of cocoa (Theobroma cacao L.) under selection in Côte d'Ivoire. Biotec., 7(1): 51-58

Kouassi KM, Kahia J, Kouame NC, Tahi GM, Koffi KE. 2017a. Comparing the effect of plant growth regulators on callus and somatic embryogenesis induction in four elite Theobroma cacao L. Genotypes. Hortsci., $\quad$ 52(1): $142-145$. http://dx.doi:10.21273/hortsci11092-16

Kouassi KM, Manlé TE, Koné D, Soumahoro AB, Koné T, Koffi KE, Koné M. 2017b. Effect of antioxidants on the callus induction and the development of somatic embryogenesis of cocoa [Theobroma cacao (L.)]. Austr. J. Crop Sci., $\quad$ 11(1): 25-31 http://dx.doi:10.21475/ajcs.2017.11.01.p ne174

Li Z, Traore A, Maximova SN, Guiltinan MJ. 1998. Somatic embryogenesis and plant regeneration from floral explants of cocoa (Theobroma cacao L.) using Thidiazuron. In vitro Cell. Dev. Biol.Plant, 34: 293-299. http://dx.doi:10.1007/ bf02822737

Lopez-Baez O, Moreno-Martmnez JL, Pacheco-Rodas S. 2000. Advances in Cocoa Theobroma cacao Propagation by Somatic Embryogenesis in Mexico. In: $3^{\text {rd }}$ Ingenic Workshop on the New Technologies and Cocoa Breeding; Kota Kinabalu, Malaysia.

Mahmood I, Razzaq A. 2017. Responses of explant type of wheat (Triticum aestivum L.) genotypes to different tissue culture media. J. Natn. Sci. Found. Sri Lanka, 45(3): $265 \quad-271, \quad$ DOI : http://dx.doi.org/10.4038/jnsfsr.v45i3.81 91

Manoharan R, Ganeshan S, Kondeti S, Gnanajothi K, Balusamy J, Sampath K, Markandan M, Andy G. 2014. 
Establishment of somatic embryogenesis and podophyllotoxin production in liquid shake cultures of Podophyllum hexandrum Royle. Ind. Crops Prod., 60: 66-74

Maximova SN, Alemano L, Youg A, Traore A, Ferrier N, Gultinan MJ. 2002. Genotype variability, efficiency and cellular origin of primary and secondary somatic embryogenesis of Theobroma cacao L. the chocolate tree. In Vitro Cell. Dev. Biol., 38: 252-259. http://dx.doi: 10.1079/IVP2001257

Minyaka E, Niemenak N, Issali EA, Sangare A, Denis NO. 2010. Sulphur depletion altered somatic embryogenesis in Theobroma cacao L. Biochemical difference related to sulphur metabolism between embryogenic and non embryogenic calli. Afric. J. Biotec., 9(35): 5665-5675.

Murashige T, Skoog F. 1962. A revised medium for rapid growth and bioassays with tobacco tissue cultures. Physiol. Plant, $\quad$ 15: $\quad 473-\quad 497$. onlinelibrary.wiley.com/doi/10.1111/j.13 99-3054.1962

Pedroso MC, Tavres R, Lino-neto T. 1996. Early events in somatic embryogenesis induction. In: Ahuja, M. R., et al., ed. Somatic cell genetics and molecular genetics of trees. The Netherlands: Kluwer Acad. Pub., 1996: 17-22.

Rusconi M, Conti A. 2010. Theobroma cacao L., the Food of the Gods: A scientific approach beyond myths and claims. Pharmacol. Res., 61(1): 5-13. http://dx.doi: 0.1016/j.phrs.2009.08.008.

Sarmadi B, Ismail I, Hamid M. 2011. Antioxidant and angiotensin converting enzyme (ACE) inhibitory activities of cocoa (Theobroma cacao L.) autolysates. Food Res. Int., 44(1): 290-296. http://dx.doi:10.1016/j.foodres.2010.10.0 17

Sarmadi B, Aminuddin F, Hamid M, Saari N, Abdul-Hamid A, Ismail A 2012. Hypoglycemic effects of cocoa (Theobroma cacao L.) autolysates. Food Chem., 134(2): 905-911. http://dx.doi:10.1016/j.foodchem.2012.0 2.202 PMID: 23107706

Subhashini R, Rao USM, Sumathi P, Gunalan G. 2010. A comparative phyto-chemical analysis of cocoa and green tea. Indian J. Sci. Tech., 3(2): 188- 192.

Thiruvengadam M, Varisai MS, Yang $\mathrm{CH}$, Jayabalan N. 2006. Development of an embryogenic suspension culture of bitter melon (Momordica charantia L.). Sci. Hort., 109: 123-129. http://dx.doi: 10.1016/j.scienta.2006.03.012

Traore A, Guiltinan M. 2006. Effects of carbon source and explants type on somatic Embryogenesis of four cacao genotypes. HortSci., 41: 753-758.

Traore A, Maximova SN, Guiltinan MJ. 2008. Micropropagation of Theobroma cacao L. using somatic embryo-derived plants. In Vitro Cell. Dev. Biol. Plant, 39: 332. https://doi.org/10.1079/IVP2002409

Yapo KD, Ouffoue SK, Okpekon TA, Kouakou TH. 2013. Soil effect on polyphenols content and antioxidant capacity of new hybrid variety of cocoa from Côte d'Ivoire. Int. J. Biol. Chem. Sci., 7(5): 1794-1803. DOI : http://dx.doi.org/10.4314/ijbcs.v7i5.1 